\title{
Influence of light intensity on surface-free energy and dentin bond strength of single-step self-etch adhesives
}

\author{
Kie NOJIRI, Akimasa TSUJIMOTO, Takayuki SUZUKI, Syo SHIBASAKI, Saki MATSUYOSHI, Toshiki TAKAMIZAWA \\ and Masashi MIYAZAKI
}

Department of Operative Dentistry, Nihon University School of Dentistry, 1-8-13 Kandasurugadai, Chiyoda-Ku, Tokyo 101-8310, Japan
Corresponding author, Akimasa TSUJIMOTO; E-mail: tsujimoto.akimasa@nihon-u.ac.jp

In this study, we investigated the influence of light intensity on the surface-free energy and dentin bond strength of single-step selfetch adhesives. The adhesives were applied to the dentin surfaces of bovine mandibular incisors and cured with light intensities of 0 (no irradiation), 200, 400, and $600 \mathrm{~mW} / \mathrm{cm}^{2}$. Surface-free energies were determined by measuring the contact angles of three test liquids placed on the cured adhesives. Dentin bond strengths of the specimens were also measured. Polymerization with a higher light intensity resulted in a lower surface-free energy of the cured adhesives. The greatest bond strength was achieved when a light intensity of $400 \mathrm{~mW} / \mathrm{cm}^{2}$ or greater was used. Our data suggest that the surface-free energy and dentin bond strength of single-step self-etch adhesives are affected by light intensity of the curing unit.

Keywords: Light intensity, Surface-free energy, Dentin bond strength, Single-step self-etch adhesive

\section{INTRODUCTION}

Current dental adhesive systems feature simplified application methods to achieve optimum clinical results ${ }^{1}$. Single-step self-etch adhesives that combine the functions of a self-etching primer and a bonding agent have been developed $^{2)}$. This kind of adhesive system combines acidic functional monomers, hydrophilic monomers, hydrophobic monomers, fillers, water, and organic solvent in a single bottle ${ }^{3)}$. The use of water as a solvent is indispensable for single-step self-etch adhesives to ensure the ionization of the acidic functional monomers, and the organic solvents are added to facilitate mixing of the hydrophilic and hydrophobic components ${ }^{4}$. However, it has been suggested that water and the solvents mixed in the adhesive resin lead to reduced mechanical properties and accordingly poorer bonding performance ${ }^{5}$. Therefore, removing these components from single-step self-etch adhesives is important for optimal bonding.

Single-step self-etch adhesives reportedly have a high hydrophilicity even after polymerization, which may increase their solubility and water uptake compared with those of conventional multi-step adhesives ${ }^{6)}$. Longterm leaching of water into the material may further compromise its mechanical properties, leading to poor bonding performance of single-step self-etch adhesives to dentin ${ }^{7}$. These phenomena may be dependent upon the degree of conversion of the adhesive, which is strongly influenced by light intensity during curing.

Light intensity during curing is dependent upon the clinical circumstances, such as cavity preparation, tooth position, or the existence of adjacent teeth ${ }^{8)}$. When the distance between the curing light tip and cavity wall increases, light intensity reaching the adhesive surface decreases ${ }^{9}$. It has been demonstrated that reduced light intensity causes lower bond strengths between self-etch adhesives and dentin ${ }^{10)}$. In addition, after the light irradiation of adhesives at a reduced light intensity, the top surface of the adhesive is covered with a relatively thick, uncured adhesive layer due to the oxygen inhibition ${ }^{11)}$. In the case of single-step selfetch adhesives, residual water and acidic functional monomers may be present within this oxygen-inhibited layer ${ }^{12)}$. The presence of water and acidic functional monomers may compromise the bonding durability of single-step self-etch adhesives. Therefore, the bonding performance of single-step self-etch adhesives may be influenced by light intensity during curing to a greater degree than the conventional multi-step adhesive systems with solvent-free bonding agents. However, there is little information on the mechanism by which the light irradiation of single-step self-etch adhesives affects dentin bond strength; therefore, it is necessary to determine the influence of light intensity on the bonding performance of these adhesives.

Previous studies ${ }^{13,14)}$ have shown that the interfacial characteristics of self-etch adhesives can be analyzed on the basis of the surface-free energy measurement. Generally, the surface-free energy characteristics of polymers make a significant contribution to their interfacial interactions with liquids, with which they can form hydrogen bonds. Wetting properties and the hydrophilicity of adhesives may be expressed in terms of the surface-free energy and its components. Thus, analysis of the surface-free energy of single-step self-etch adhesives may provide an insight in the development of their bonding performance.

In this study, we examined the influence of light intensity during curing on the surface-free energy of adhesive-treated dentin and bond strength of single-step self-etch adhesives to bovine dentin. Our null hypothesis was that there would be no significant differences in surface-free energy or bond strength at different light intensities. 


\section{MATERIALS AND METHODS}

Adhesives used

As presented in Table 1, the single-step self-etch adhesive systems used were: Scotchbond ${ }^{\mathrm{TM}}$ Universal Adhesive (3M ESPE, St. Paul, MN, USA); Clearfil ${ }^{\mathrm{TM}}$ Tri-S Bond (Kuraray Noritake Dental, Tokyo, Japan); and G-Bond ${ }^{\mathrm{TM}}$ Plus (GC, Tokyo, Japan).

A visible-light curing unit (Optilux 501, Demetron Kerr, Danbury, CT, USA) was connected to a variablevoltage transformer (Type S-130-10, Yamabishi Electric, Tokyo, Japan). The light intensities used were 100, 200, 400 , and $600 \mathrm{~mW} / \mathrm{cm}^{2}$; these values were determined using a dental curing radiometer (Model 100, Demetron Kerr). The curing unit was placed in a jig to maintain the distance between the light tip end and specimen surface $(2 \mathrm{~mm})$.

\section{Surface-free energy measurement}

Mandibular incisors were extracted from 2- to 3-yearold cattle and frozen until use. After removing the roots of each tooth with a slow-speed saw equipped with a diamond-impregnated disk (IsoMet ${ }^{\circledR}$, Buehler, Lake Bluff, IL, USA), the pulp was removed, and the pulp chamber was filled with cotton to avoid penetration of the embedding medium. After ultrasonic cleaning for $1 \mathrm{~min}$ in distilled water to remove debris, the surface of each tooth was washed and then dried with oil-free compressed air. The labial surface was ground with wet 240-grit silicon carbide ( $\mathrm{SiC}$ ) paper to create a flat dentin surface. Each tooth was then mounted in selfcuring acrylic resin (Tray Resin II, Shofu, Kyoto, Japan) to expose the flattened area, and placed under tap water to reduce the temperature increase caused by the exothermic polymerization reaction of the acrylic resin. The final finish was created by grinding with wet 320 grit SiC paper. Finally, the dentin surface of each tooth was dried with oil-free compressed air.

Each adhesive was applied to the dentin surface according to the manufacturers' instructions, followed by light irradiation for $10 \mathrm{~s}$. Light irradiation was performed at intensities of 0 (no irradiation), 200, 400, and $600 \mathrm{~mW} / \mathrm{cm}^{2}$. Surface-free energy was determined by measuring the contact angle with the surface of three test liquids, 1-bromonaphthalene, diiodomethane, and distilled water, each of which has known surface-free energy parameters (Table 2). The surface-free energy of five specimens per light intensity group for each adhesive-treated dentin surface was determined by measuring their contact angle (Drop Master DM500, Kyowa Interface Science, Saitama, Japan). The device was fitted with a charge-coupled device camera, which allowed automatic measurement of the contact angle (Fig. 1). For each test liquid, the equilibrium contact angle $(\theta)$ was measured, using the sessile-drop method at $23 \pm 1^{\circ} \mathrm{C}$, for five specimens of each adhesive ${ }^{15)}$. The surface free-energy parameters of the solids were then determined based on the fundamental concepts of wetting.

The Young-Dupré equation describes the work of adhesion (W) between a solid (S) and a liquid (L) in contact as follows:

Table 1 Single-step self-etch adhesives used in this study

\begin{tabular}{lcccc}
\hline \multicolumn{1}{c}{ Adhesive } & Code & Lot No. & Main components & Manufacturer \\
\hline $\begin{array}{l}\text { Scotch Bond } \\
\text { Universal }\end{array}$ & SU & 541424 & $\begin{array}{c}\text { MDP, Bis-GMA, HEMA, Vitrebond } \\
\text { copolymer, polyethelene glycol, water, } \\
\text { initiator, colloidal silica, aluminiam oxide }\end{array}$ & $\begin{array}{c}\text { 3M ESPE, St. Paul, } \\
\text { MN, USA }\end{array}$ \\
$\begin{array}{l}\text { Clearfil } \\
\text { Tri-S Bond }\end{array}$ & TS & 00038B & $\begin{array}{c}\text { MDP, Bis-GMA, HEMA, ethanol,water, } \\
\text { initiator, silanated colloidal silica }\end{array}$ & $\begin{array}{c}\text { Kuraray Noritake Dental, } \\
\text { Tokyo, Japan }\end{array}$ \\
$\begin{array}{l}\text { G-Bond } \\
\text { Plus }\end{array}$ & GB & 1312131 & $\begin{array}{c}\text { MDP, 4-MET, methacrylate monomer, } \\
\text { acetone, water, initiator, silica filler }\end{array}$ & GC, \\
\hline
\end{tabular}

MDP: 10-methacryloyloxydecyl di-hydrogen phosphate, Bis-GMA: 2,2-bis[4-(2-hydroxyl-3-methacryloyloxypropoxy)phenyl] propane, HEMA: 2-hydroxyethyl methacrylate, 4-MET: 4-methacryloyloxyethyl trimellitate

Table 2 Surface free energy and their components values of test

\begin{tabular}{|c|c|c|c|c|c|c|}
\hline Liquid & Lot No. & Manufacturer & $\gamma_{\mathrm{L}}$ & $\gamma_{L}{ }^{d}$ & $\gamma_{\mathrm{L}}^{\mathrm{p}}$ & $\gamma_{\mathrm{L}}^{\mathrm{h}}$ \\
\hline 1-Bromonaphthalene & ALH4513 & Wako Pure Chemical Industries & 44.6 & 44.4 & 0.2 & 0.0 \\
\hline Diiodomethane & ALL2310 & Wako Pure Chemical Industries & 50.8 & 46.8 & 4.0 & 0.0 \\
\hline Distilled water & - & - & 72.8 & 29.1 & 1.3 & 42.4 \\
\hline
\end{tabular}

Unit: $\mathrm{mN} / \mathrm{m}$.

$\gamma_{\mathrm{L}}$ : surface free energy, $\gamma_{\mathrm{L}}{ }^{\mathrm{d}}$ : dispersion force, $\gamma_{\mathrm{L}}^{\mathrm{p}}$ : polarity force, $\gamma_{\mathrm{L}}^{\mathrm{h}}$ : hydrogen bonding force 


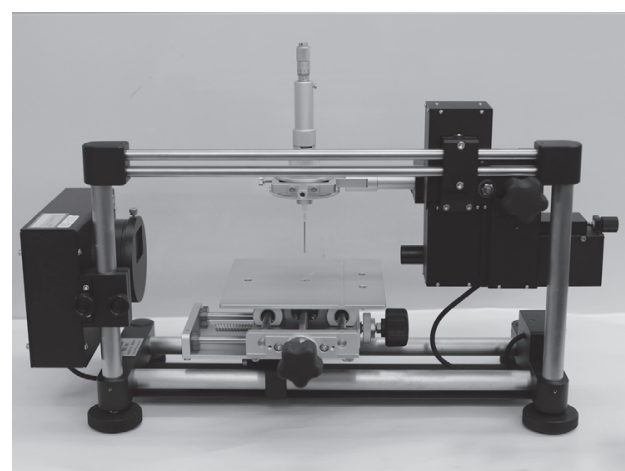

(a)

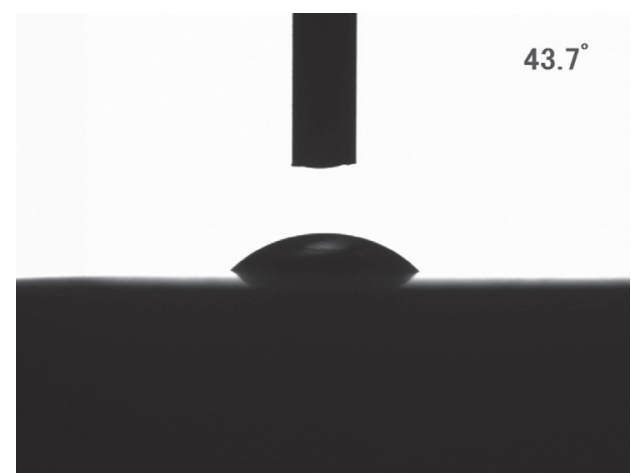

(b)

Fig. 1 Drop Matser DM500 apparatus fitted with a charge-coupled device camera (a) allowing automatic measurements of the contact angles to be made (b).

$$
\mathrm{W}_{\mathrm{SL}}=\gamma_{\mathrm{L}}+\gamma_{\mathrm{S}}-\gamma_{\mathrm{SL}}=\gamma_{\mathrm{L}}(1+\cos \theta)
$$

Here, $\gamma_{\mathrm{SL}}$ is the interfacial free energy between the solid and liquid, $\gamma_{\mathrm{L}}$ is the surface-free energy of the liquid, and $\gamma_{S}$ is the surface-free energy of the solid. By extending the Fowkes equation, the $\gamma_{\mathrm{SL}}$ can be expressed as follows:

$$
\begin{aligned}
& \gamma_{S L}=\gamma_{L}+\gamma_{S}-2\left(\gamma_{L}{ }^{d} \gamma_{S}{ }^{d}\right)^{1 / 2}-2\left(\gamma_{L}{ }^{p} \gamma_{S}{ }^{p}\right)^{1 / 2}-2\left(\gamma_{L}{ }^{h} \gamma_{S}^{h}\right)^{1 / 2} \\
& \gamma_{L}=\gamma_{L}{ }^{d}+\gamma_{L}^{p}+\gamma_{L}^{h}, \gamma_{S}=\gamma_{S}{ }^{d}+\gamma_{S}{ }^{p}+\gamma_{S}^{h}
\end{aligned}
$$

where $\gamma_{\mathrm{L}}^{\mathrm{d}}, \gamma_{\mathrm{L}}^{\mathrm{p}}$, and $\gamma_{\mathrm{L}}^{\mathrm{h}}$ are components of the surface-free energy $(\gamma)$ arising from the dispersion force, the polar (permanent and induced) force, and the hydrogenbonding force, respectively. Surface-free energy $(\gamma)$ values were determined for the three test liquids, and the surface energy parameters of the treated dentin surfaces were calculated based on these equations using add-on software and an interface measurement and analysis system (FAMAS, Kyowa Interface Science).

\section{Bond strength measurement}

The shear-bond strength between the single-step selfetch adhesives and the dentin surface was measured by a notched-edge shear-bond strength test, as described by ISO 29022 ${ }^{16)}$. A total of 120 mandibular incisors from cattle were prepared as described in the preceding section. The adhesives were applied according to the manufacturers' instructions, followed by light irradiation for $10 \mathrm{~s}$. Light irradiation was performed at intensities of 0 (no irradiation), 200, 400, and 600 $\mathrm{mW} / \mathrm{cm}^{2}$. The specimens were clamped in a bonding jig (Ultradent Bonding Jig, Ultradent Products, South Jordan, UT, USA), and plastic molds (2.4 $\mathrm{mm}$ in internal diameter, $2.5 \mathrm{~mm}$ in height) were used to form and hold the resin composite on the adhesive-treated dentin surface. The resin composite (Clearfil ${ }^{\mathrm{TM}}$ AP-X, Kuraray Noritake Dental) was condensed into the mold and light cured for $30 \mathrm{~s}$ at a light intensity of $600 \mathrm{~mW} / \mathrm{cm}^{2}$. The finished specimens were transferred to distilled water, and stored at $37^{\circ} \mathrm{C}$ for $24 \mathrm{~h}$.
Ten specimens per light intensity were tested in shear mode using bond-testing notched-blade semicircular apparatus (Ultradent Products) in a universal testing machine (Type 5500R, Instron, Norwood, MA, USA) at a crosshead speed of $1 \mathrm{~mm} / \mathrm{min}$. Bond strength values $(\mathrm{MPa})$ were calculated from the peak load at failure divided by the specimen surface area. After testing, the specimens were examined under an optical microscope (SZH-131, Olympus, Tokyo, Japan) at a magnification of $\times 10$ to determine the location of bond failure. The type of failure was classified based on the percentage of substrate-free material as follows: adhesive failure; cohesive failure in the dentin; or cohesive failure in the composite.

\section{Statistical analysis}

The dentin bond strength data obtained were analyzed using a commercial statistical software package (SigmaStat Version 3.1, SPSS, Chicago, IL, USA). Because the data were normally distributed (KolmogorovSmirnov test), two-way analysis of variance (ANOVA) was used to analyze the effects of light intensities and the adhesive systems that were used. Multiple comparisons were then conducted using the TukeyKramer test, with a significance level of 0.05 .

\section{Scanning electron microscopy}

The resin-dentin interface was ultrastructurally observed by scanning electron microscopy (SEM). Bonded specimens from each group $(n=5)$ were stored in distilled water maintained at $37^{\circ} \mathrm{C}$ for $24 \mathrm{~h}$, embedded in self-curing epoxy resin (Epon812, Nisshin EM, Tokyo, Japan), and stored at $37^{\circ} \mathrm{C}$ for an additional 12 $\mathrm{h}$. The embedded specimens were sectioned through the diameter of the composite resin post, and the surfaces of the cut halves were polished with an Ecomet 4/Automet 2 (Buehler) using SiC papers with a grit size of 600 , 1,200 , and 4,000 in succession. The surface was finally polished by a soft cloth using diamond paste (Buehler) with a grit size of $1.0 \mathrm{~lm}$. All SEM specimens were dehydrated in ascending concentrations of tert-butanol 
(50\% for $20 \mathrm{~min}, 75 \%$ for $20 \mathrm{~min}, 95 \%$ for $20 \mathrm{~min}$, and $100 \%$ for $2 \mathrm{~h}$ ) and transferred to a critical-point dryer for $30 \mathrm{~min}$. These surfaces were subjected to Argon ion-beam etching (Type EIS-200ER, Elionix, Tokyo, Japan) for 30 $\mathrm{s}$, with the ion beam (accelerating voltage, $1.0 \mathrm{kV}$, ion current density, $\left.0.4 \mathrm{~mA} / \mathrm{cm}^{2}\right)$ directed perpendicularly to the polished surface. Surfaces were coated in a vacuum evaporator (Quick Coater Type SC-701, Sanyu Denshi, Tokyo, Japan) with a thin film of gold and observed by SEM (ERA 8800FE, Elionix) at an accelerating voltage of $10 \mathrm{kV}$. All of the specimens were observed under SEM.

\section{RESULTS}

The surface free energies and their components, for each cured adhesive, are shown in Table 3. Total surfacefree energy $\left(\gamma_{S}=\gamma_{S}{ }^{d}+\gamma_{S}{ }^{p}+\gamma_{S}{ }^{h}\right)$ values decreased with increasing light intensity, and were significantly lower when adhesives were irradiated with a light intensity of $400 \mathrm{~mW} / \mathrm{cm}^{2}$. For all surfaces, the estimated $\gamma_{\mathrm{s}}{ }^{\mathrm{d}}$ values remained relatively constant, in the range of 38.3-39.8 $\mathrm{mN} / \mathrm{m}$. Decreased $\gamma_{\mathrm{s}}{ }^{\mathrm{p}}$ and $\gamma_{\mathrm{s}}{ }^{\mathrm{h}}$ values were observed for specimens irradiated with a greater light intensity.

The influence of light intensity during curing on shear bond strength is shown in Table 4. Two-way ANOVA revealed that both adhesive type $(p<0.001)$ and light intensity $(p<0.001)$ significantly influenced bond strength, although there was no significant interaction between the two factors $(p=0.601)$. For each adhesive, greater bond strength was achieved by irradiation with a light intensity of $400 \mathrm{~mW} / \mathrm{cm}^{2}$ or greater. Statistically significant differences were evident between the values obtained, except for those obtained at light intensities of 400 and $600 \mathrm{~mW} / \mathrm{cm}^{2}(p<0.005)$. Failure type was not associated with bond strength: the predominant failure type was adhesive failure.

SEM observations of the resin-dentin interface are shown in Fig. 2. The dentin-resin interface of each groups showed excellent adaptation, with the formation of a transitional layer between the adhesive resin and

Table 3 Influence of light intensity on surface free energies and their components for single-step self-etch adhesives

\begin{tabular}{|c|c|c|c|c|c|}
\hline & & $\gamma_{\mathrm{S}}$ & $\gamma_{\mathrm{s}}^{\mathrm{d}}$ & $\gamma_{S^{p}}^{p}$ & $\gamma_{\mathrm{S}}^{\mathrm{h}}$ \\
\hline \multirow{4}{*}{ SU } & 0 & $73.5(3.2)$ & $38.5(0.8) \square$ & $10.6(2.0) \square$ & $24.4(2.3)$ \\
\hline & 200 & $68.0(3.1)$ & $39.1(0.7)$ & $8.3(2.0)-$ & $20.6(2.2)$ \\
\hline & 400 & $55.1(3.4)$ & $39.6(1.0)-$ & $5.3(2.7)$ & $10.2(1.8)$ \\
\hline & 600 & $54.8(2.5)$ & $39.8(0.8)$ & $4.9(2.0)$ & $10.1(1.2)$ \\
\hline \multirow{4}{*}{ TS } & 0 & $72.2(3.1)$ & $38.9(0.6) \square$ & $9.8(2.2) \square$ & $23.5(2.1)$ \\
\hline & 200 & $67.7(3.6)$ & $38.7(1.2)-$ & $9.6(2.8)$ & $19.4(1.9)$ \\
\hline & 400 & $57.2(3.5)$ & $38.9(1.1)$ & $7.7(2.7)$ & $10.6(1.9)$ \\
\hline & 600 & $57.1(3.0)-$ & $39.1(0.9)-$ & $6.8(2.2)$ & $11.2(1.8)$ \\
\hline \multirow{4}{*}{ GB } & 0 & $69.0(3.3)$ & $38.5(1.2) \square$ & $10.2(2.2) \square$ & $20.3(2.2)$ \\
\hline & 200 & $64.3(3.2)$ & $38.3(0.8)-$ & $9.3(2.2)$ & $16.7(2.2)$ \\
\hline & 400 & $57.2(2.4)$ & $39.8(0.9)-$ & $5.4(1.5)$ & $12.0(1.7)$ \\
\hline & 600 & $57.6(2.0)-$ & $39.9(1.2)-$ & $5.1(1.9)$ & $12.6(2.0)$ \\
\hline
\end{tabular}

Unit: $\mathrm{mN} / \mathrm{m}$, values in parenthesis are standard deviations $(n=5)$.

Values connected by vertical lines indicate no significant difference $(p>0.05)$.

Table 4 Influence of light intensity on dentin bond strength of single-step self-etch adhesives

\begin{tabular}{|c|c|c|c|c|}
\hline \multirow{2}{*}{ Adhesive } & \multicolumn{4}{|c|}{ Light intensity } \\
\hline & 0 & 200 & 400 & 600 \\
\hline SU & $\begin{array}{c}18.8(3.2)^{\mathrm{a}, \mathrm{A}} \\
{[10 / 0 / 0]}\end{array}$ & $\begin{array}{c}24.8(3.7)^{\mathrm{a}, \mathrm{B}} \\
{[10 / 0 / 0]}\end{array}$ & $\begin{array}{c}30.3(3.7)^{\mathrm{a}, \mathrm{C}} \\
{[10 / 0 / 0]}\end{array}$ & $\begin{array}{c}29.2(3.2)^{\mathrm{a}, \mathrm{C}} \\
{[10 / 0 / 0]}\end{array}$ \\
\hline $\mathrm{TS}$ & $\begin{array}{c}15.5(2.8)^{\mathrm{b}, \mathrm{A}} \\
{[10 / 0 / 0]}\end{array}$ & $\begin{array}{c}19.2(4.4)^{\mathrm{b}, \mathrm{B}} \\
{[10 / 0 / 0]}\end{array}$ & $\begin{array}{c}27.9(3.8)^{\mathrm{b}, \mathrm{C}} \\
{[10 / 0 / 0]}\end{array}$ & $\begin{array}{c}27.3(3.2)^{b, C} \\
{[10 / 0 / 0]}\end{array}$ \\
\hline GB & $\begin{array}{c}15.3(3.5)^{\mathrm{b}, \mathrm{A}} \\
{[10 / 0 / 0]}\end{array}$ & $\begin{array}{c}19.0(3.4)^{\mathrm{b}, \mathrm{B}} \\
{[10 / 0 / 0]}\end{array}$ & $\begin{array}{c}25.3(3.9)^{\mathrm{b}, \mathrm{C}} \\
{[10 / 0 / 0]}\end{array}$ & $\begin{array}{c}26.0(3.0)^{\mathrm{b}, \mathrm{C}} \\
{[10 / 0 / 0]}\end{array}$ \\
\hline
\end{tabular}

Unit: MPa, values in parenthesis are standard deviations $(n=15)$.

Values with same letter indicate no significant difference $(p>0.05)$.

[ ] : failure mode [adhesive failure/ cohesive failure/ mixed failure] 


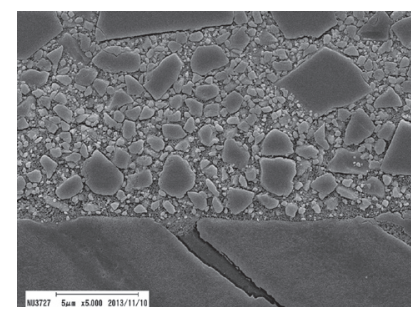

(a)

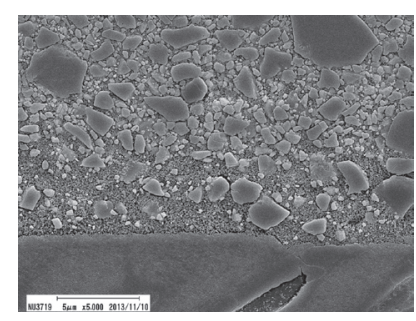

(b)

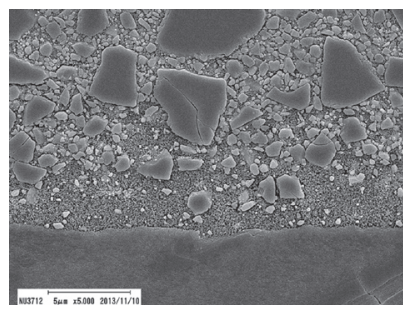

(c)

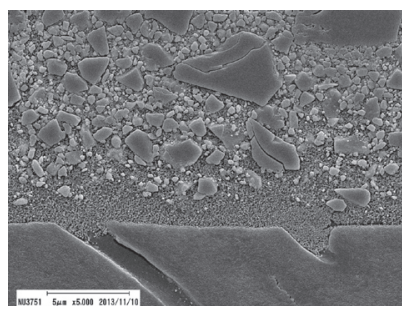

(d)

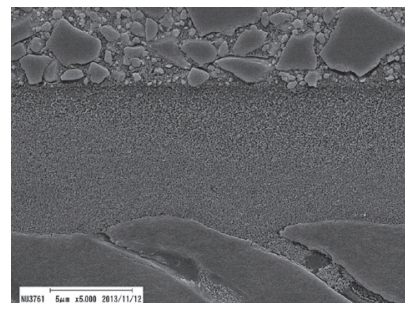

(e)

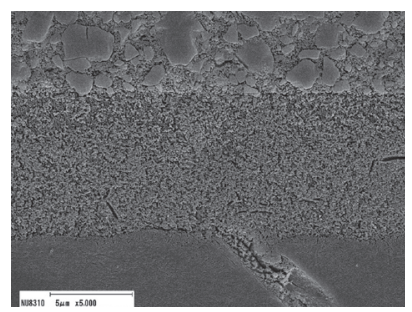

(f)

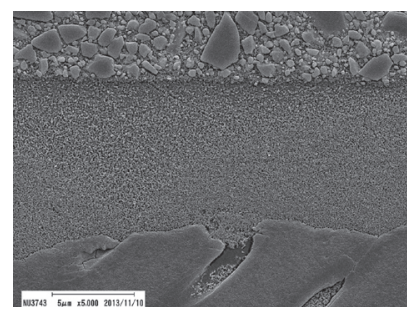

(g)

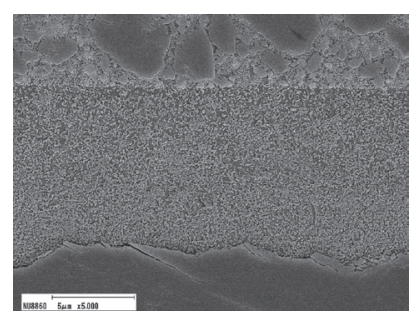

(h)

Fig. 2 Representative SEM photomicrographs of the dentin-resin interface (Original magnification, $\times 5,000)$. Thickness of adhesive was indicated by white arrows in each SEM. (a) SU with $0 \mathrm{~mW} / \mathrm{cm}^{2}$, (b) TS with $0 \mathrm{~mW} / \mathrm{cm}^{2}$, (c) SU with $200 \mathrm{~mW} / \mathrm{cm}^{2}$, (d) TS with $400 \mathrm{~mW} / \mathrm{cm}^{2}$, (e) SU with $400 \mathrm{~mW} / \mathrm{cm}^{2}$, (f) TS with 400 $\mathrm{mW} / \mathrm{cm}^{2}$, (g) SU with $600 \mathrm{~mW} / \mathrm{cm}^{2}$, (h) TS with $600 \mathrm{~mW} / \mathrm{cm}^{2}$.

tooth structure. The thickness of the adhesives was lesser for the specimens irradiated with a weaker light intensity of $<200 \mathrm{~mW} / \mathrm{cm}^{2}$.

\section{DISCUSSION}

Generally, the surface-free energy of organic substances $\left(\gamma_{\mathrm{S}}\right)$ has three component forces: the dispersion $\left(\gamma_{\mathrm{S}}{ }^{\mathrm{d}}\right)$, polarity $\left(\gamma_{\mathrm{S}}{ }^{\mathrm{p}}\right)$, and hydrogen-bonding $\left(\gamma_{\mathrm{S}}{ }^{\mathrm{h}}\right)$ forces ${ }^{17)}$. The dispersion force represents London interactions between apolar molecules, whereas the polar (nondispersion) force represents electrostatic, metallic, and dipolar interactions. Further to these two parameters of the $\gamma_{\mathrm{S}}$, we also calculated the hydrogen-bonding force, which is related to water and hydroxyl components. Because the hydration of the adherend is of great importance to wettability — which is, in turn, key to dentin bondingpolar interactions and hydrogen-bonding characteristics must be accurately determined to clarify the interactions between the adhesives and water ${ }^{18)}$. An estimation of dipolar interactions separately from hydrogen-bonding interactions may provide a novel insight into the mechanisms contributing to wettability and the bonding characteristics of the adhesives.

The $\gamma_{\mathrm{S}}{ }^{\mathrm{d}}$ values of the dentin surfaces remained relatively constant $(38.3-39.8 \mathrm{mN} / \mathrm{m})$ regardless of the adhesive used, and there were no significant differences in $\gamma_{\mathrm{S}}{ }^{\mathrm{d}}$ between light intensity groups. Reportedly, the $\gamma_{\mathrm{s}}{ }^{\mathrm{d}}$ values of many oxidized surfaces measured using this method are approximately $40 \mathrm{mN} / \mathrm{m}^{12,15,19)}$, whereas those of surfaces coated with polytetrafluoroethylene are around $20 \mathrm{mN} / \mathrm{m}$.
The $\gamma_{\mathrm{S}}{ }^{\mathrm{p}}$ values of all specimens were relatively low (from 4.9 to $10.6 \mathrm{mN} / \mathrm{m}$ ), and decreased with increasing light intensity. The $\gamma_{\mathrm{S}}{ }^{\mathrm{h}}$ values ranged from 16.7 to $24.4 \mathrm{mN} / \mathrm{m}$ at light intensities of 0 and $200 \mathrm{~mW} / \mathrm{cm}^{2}$, and from 10.1 to $12.6 \mathrm{mN} / \mathrm{m}$ at light intensities of 400 $\mathrm{mW} / \mathrm{cm}^{2}$ or greater. The $\gamma_{\mathrm{s}}{ }^{\mathrm{p}}$ value, which reflects polar interactions, and the $\gamma_{\mathrm{S}}{ }^{\mathrm{h}}$ value, which relates to water and hydroxyl components, together measure hydrophilic interactions. The functional monomers of the adhesives used have three distinct structural components: functional, spacer, and polymerizable groups ${ }^{20)}$. The functional group exhibits hydrophilic properties that enhance the wettability and demineralization of the tooth surface ${ }^{21)}$. The spacer group influences the properties of the monomer, including water solubility, viscosity, wettability, and penetration ${ }^{22)}$. However, after light irradiation at sufficient light intensities, the polymerizable groups of the functional monomers become polymerized, increasing the hydrophobicity of the cured adhesive ${ }^{23)}$. Therefore, sufficient light energy may enhance the polymerization reaction and encourage the double-bond conversion of resin monomers in the adhesives. Conversely, incomplete polymerization may lead to residual water within the adhesive ${ }^{24)}$. Irradiation of the adhesive at a lower light intensity may impair cross-linking within the adhesive as a result of insufficient cross-linked functional monomers and excess water within the adhesive; this may lead to higher $\gamma_{\mathrm{S}}^{\mathrm{p}}$ and $\gamma_{\mathrm{S}}{ }^{\mathrm{h}}$ values in adhesives irradiated at a lower light intensity.

When the adhesives were cured at a greater light intensity, the resultant dentin bond strength values 
were higher than those obtained when the adhesives were polymerized with a light intensity of $200 \mathrm{~mW} /$ $\mathrm{cm}^{2}$ or less. From SEM observation of the dentin-resin interface, the thickness of the adhesive was much less in the group irradiated with a weaker light intensity. These data suggest that the adhesives acquire inferior mechanical properties as a result of insufficient polymerization by inadequate light energy, in turn reducing bond strength. Furthermore, irradiation of single-step self-etch adhesives at a lower light intensity retards the polymerization process, leading to the creation of a thicker, uncured adhesive layer that includes an oxygen-inhibited layer ${ }^{25}$. Presumably, residual acidic functional monomers, water, and solvent are present in this oxygen-inhibited layer ${ }^{12}$. These remnants may impair the secondary polymerization of the adhesive and the polymerization of the filler resin, because tertiary amines in the adhesives and filler resin composite may be neutralized by the acidic functional monomers in the uncured adhesive ${ }^{26}$. Acidic conditions affect polymerization driven by dl-camphorquinone/ amine catalysts, resulting in poor polymerization and attenuating interactions with the filler resin composite $^{27}$.

In this study, when the surface-free energy of single-step adhesives decreased following irradiation at a greater light intensity, dentin bond strength values increased. Optimal wettability is essential to enable the materials to spread across the entire surface and establish adhesion ${ }^{28}$. Although in general, the surfacefree energy of the adherend surface must be maximized, the maximum bond strength was evident in properly polymerized adhesives, which have a lower surface-free energy $^{14}$. Therefore, full polymerization of the adhesive has a greater influence on shear bond strength than the surface-free energy of the adhesive. This suggests that the degree of polymerization of adhesives with a lower surface-free energy significantly influenced dentin-bond strength. Our null hypothesis that there would be no significant differences in surface-free energy and bond strength at different light intensities, can therefore be rejected.

\section{CONCLUSION}

Regarding the single-step self-etch adhesives evaluated in this study, polymerization with a greater light intensity reduced the surface-free energy of adhesivetreated dentin surfaces, because conversion of the polymerizable group of functional monomers was enhanced. Sufficient light energy may enhance the polymerization reaction and perpetuate the doublebond conversion of resin monomers in the adhesives, leading to higher dentin bond strength. When the single-step self-etch adhesives were polymerized with a light intensity of $200 \mathrm{~mW} / \mathrm{cm}^{2}$ or less, stronger polarity and hydrogen-bonding forces were evident in the adhesives, leading to inferior bonding performance, possibly due to suboptimal polymerization or the influence of residual acidic functional monomers and water. These data suggest that dentin bond strength and the polymerization behavior of single-step self-etch adhesives are affected by light intensity during curing.

\section{ACKNOWLEDGMENTS}

This work was supported in part by a Grant-in-Aid for Scientific Research (C) 26462896 and a Grant-in-Aid for Young Scientists (B) 10608409 from the Japan Society for the Promotion of Science. This project was also supported in part by the Sato Fund and by a grant from the Dental Research Center of the Nihon University School of Dentistry, Japan.

\section{REFERENCES}

1) Cardoso MV, de Almeida Neves A, Mine A, Coutinho E, Van Landuyt K, De Munck J, Van Meerbeek B. Current aspects on bonding effectiveness and stability in adhesive dentistry. Aust Dent J 2011; 56: 31-44.

2) Perdigão J. New developments in dental adhesion. Dent Clin North Am 2007; 51: 333-357.

3) Van Landuyt KL, Snauwaert J, De Munck J, Peumans M, Yoshida Y, Poitevin A, Coutinho E, Suzuki K, Lambrechts P, Van Meerbeek B. Systematic review of the chemical composition of contemporary dental adhesives. Biomaterials 2007; 28: 3757-3785.

4) Van Meerbeek B, Yoshihara K, Yoshida Y, Mine A, De Munck J, Van Landuyt KL. State of the art of self-etch adhesives. Dent Mater 2011; 27: 17-28.

5) Jacobsen T, Finger WJ, Kanehira M. Air-drying time of selfetching adhesives vs bonding efficacy. J Adhes Dent 2006; 8: 387-392.

6) Tay FR, Pashley DH, Suh BI, Carvalho RM, Itthagarun A. Single-step adhesives are permeable membranes. J Dent 2002; 30: 371-382.

7) Reis AF, Giannini M, Pereira PN. Influence of water-storage time on the sorption and solubility behavior of current adhesives and primer/adhesive mixtures. Oper Dent 2007; 32: 53-59.

8) Mutluay MM, Rueggeberg FA, Price RB. Effect of using proper light-curing techniques on energy delivered to a Class 1 restorations. Quintessence Int 2014; 45: 549-556.

9) Seki N, Nakajima M, Kishikawa R, Hosaka K, Foxton RE, Tagami J. The influence of light intensities irradiated directly and indirectly through resin composite to self-etch adhesives on dentin bonding. Dent Mater J 2011; 30: 315-322.

10) Benetti AR, Asmussen E, Peutzfeldt A. Influence of curing rate of resin composite on the bond strength to dentin. Oper Dent 2007; 32: 144-148.

11) Gauthier MA, Stangel I, Ellis TH, Zhu XX. Oxygen inhibition in dental resins. J Dent Res 2005; 84: 725-729.

12) Koga K, Tsujimoto A, Ishii R, Iino M, Kotaku M, Takamizawa T, Tsubota K, Miyazaki M. Influence of oxygen inhibition on the surface free-energy and dentin bond strength of self-etch adhesives. Eur J Oral Sci 2011; 119: 395-400.

13) Combe EC, Owen BA, Hodges JS. A protocol for determining the surface free energy of dental materials. Dent Mater 2004; 20: $262-268$.

14) Asmussen E, Peutzfeldt A. Resin composites: strength of the bond to dentin versus surface energy parameters. Dent Mater 2005; 11: 1039-1043.

15) Tsujimoto A, Iwasa M, Shimamura $Y$, Murayama R, Takamizawa T, Miyazaki M. Enamel bonding of singlestep self-etch adhesives: Influence of surface free energy characteristics. J Dent 2010; 38: 123-130.

16) International Organization for Standardization. ISO 29022 
2013 Dentistry Adhesion Notched-edge shear bond strength test. ISO 2013.

17) Hata T, Kitazaki Y, Saito T. Estimation of the surface free energy of polymer solids. J Adhesion 1987; 21: 177-194.

18) Grégoire G, Dabsie F, Dieng-Sarr F, Akon B, Sharrock P. Solvent composition of one-step self-etch adhesives and dentine wettability. J Dent 2011; 39: 30-39.

19) Shimizu Y, Tsujimoto A, Furuichi T, Suzuki T, Tsubota K, Miyazaki M, Platt JA. Influence of light intensity on surface free energy and dentin bond strength of core build-up resins. Oper Dent 2015; 40: 87-95.

20) Van Landuyt KL, Yoshida Y, Hirata I, Snauwaert J, De Munck J, Okazaki M, Suzuki K, Lambrechts P, Van Meerbeek B. Influence of the chemical structure of functional monomers on their adhesive performance. J Dent Res 2008; 87: 757761.

21) Iwai H, Nishiyama N. Effect of calcium salt of functional monomer on bonding performance. J Dent Res 2012; 91: 1043-1048.

22) Feitosa VP, Ogliari FA, Van Meerbeek B, Watson TF, Yoshihara K, Ogliari AO, Shinhoreti MA, Correr AB, Cama G, Sauro S. Can the hydrophilicity of functional monomers affect chemical interaction? J Dent Res 2014; 93: 201-206.
23) Moszner N, Salz U, Zimmermann J. Chemical aspects of selfetching enamel-dentin adhesives: A systematic review. Dent Mater 2005; 21: 895-910.

24) Hosaka K, Nakajima M, Takahashi M, Itoh S, Ikeda M, Tagami J. Relationship between mechanical properties of one-step self-etch adhesives and water sorption. Dent Mater 2010; 26: 360-367.

25) Hashimoto M, Fujita S, Kaga M, Yawaka Y. In vitro durability of one-bottle resin adhesives bonded to dentin. Dent Mater J 2007; 26: 677-686.

26) Tay FR, Pashley DH, Yiu CK, Sanares AM, Wei SH. Factors contributing to the incompatibility between simplified-step adhesives and chemically-cured of dual cured composites. Part I. Single-step self-etching adhesives. J Adhes Dent 2003; 5: 27-40.

27) Sanares AM, Itthagarun A, King NM, Tay FR, Pashley DH. Adverse surface interactions between one-bottle light-cured adhesives and chemical-cured composites. Dent Mater 2001; 17: 542-556.

28) Rosales-Leal JI, Osorio R, Holgado-Terriza JA, CabrerizoVílchez MA, Toledano M. Dentin wetting by four adhesive systems. Dent Mater 2001; 17: 526-532. 